\title{
Kant e o problema da coisa em si \\ Perspectiva de uma reflexão racional
}

\author{
Fernando Costa Mattos*
}

\begin{abstract}
Resumo: O texto discute o problema da coisa em si kantiana apresentando duas possíveis visões sobre ele: a polêmica posição de Bernard Rousset (em La doctrine kantienne de l'objectivité) e a de Gérard Lebrun (em Sobre Kant). A última é considerada mais plausível no que diz respeito ao projeto kantiano.
\end{abstract}

Palavras-chave: coisa em si - idealismo - realismo - racional

Ao se analisar a solução elaborada por Kant para o problema do conhecimento, é notadamente difícil decidir se o objeto que 'nos é dado' na intuição sensível tem ou não uma existência autônoma em relação ao sujeito. A despeito da afirmação de que a matéria do conhecimento, por oposição à forma, não é fornecida pelo sujeito, e sim por ele passivamente recebida, mantém-se a possibilidade de supor dois níveis de subjetividade - um, dito interno, correspondente ao papel ativo do sujeito; e outro, dito externo, correspondente ao seu papel passivo - e, conseqüentemente, de supor a completa dependência do objeto (inclusive quanto ao seu existir) em relação ao sujeito, no sentido mais forte da afirmação de que 'sem sujeito, não há objeto'. Em sentido inverso, porém, a exterioridade do objeto pode também ser interpretada como absoluta, e ele tomado como existindo independentemente do sujeito. Ambas as leituras, com efeito - a primeira fazendo de Kant um idealista, e a segunda, um realista -, bem como muitas outras 'intermediárias', contam com numerosos adeptos desde o tempo do aparecimento da obra kantiana (cf. Delbos 2, p. 139 e ss.),

\footnotetext{
* Mestrando do Departamento de Filosofia - FFLCH-USP e bolsista FAPESP.
} 
e se esta própria, que deveria servir de critério decisório, não parece arrefecer a dúvida, a posição ideal, muitas vezes, é deixar a questão de lado, sob pena de enveredar por aporias incontornáveis. Em face, contudo, da importância do tema, sobretudo tendo-se em vista a relação entre os âmbitos teórico e prático, não parece poder ser este o presente caso.

É comum vermos sustentada, principalmente entre seus críticos, a tese de que Kant teria adotado mais firmemente a posição idealista na primeira edição da Crítica da razão pura, para depois 'voltar atrás' e, na segunda edição, introduzir trechos de cunho realista ${ }^{1}$ (como de resto é comum ouvir-se que Kant 'voltou atrás' em relação a suas posições epistemológicas mais 'duras' para permitir flexibilizações conceituais como a própria admissão de um conhecimento prático). Ainda que, de fato, os trechos que ensejam interpretação realista sejam mais escassos na primeira edição que na segunda, e que se tenha dado apenas nesta última a introdução da célebre passagem 'Refutação ao Idealismo’ (Kant 4, B 274-279), isto não parece alterar o panorama geral de aparente ambigüidade criado pelas diversas passagens que, em ambas as edições, e também nos Prolegômenos, ora ensejam uma interpretação, ora outra, e ora as duas ao mesmo tempo (conforme o ângulo que se adote). Por outro lado, não é de todo desarrazoado levar em conta a declaração de intenções feita pelo próprio Kant no prefácio à segunda edição, em que afirma não ter introduzido quaisquer mudanças com relação ao conteúdo da obra (Kant 4, B XXXVII) ${ }^{2}$ e, aceitando-a, tentar examinar a questão, sem a pressa de assumir rótulos, em vista do espírito geral da obra.

Tendo-se em vista a inserção de Kant no panorama histórico da filosofia moderna, é de se reconhecer, a despeito do cunho revolucionário que sua obra pretende ter, que ele se mantém em consonância com algumas das principais tendências de seus antecessores, notadamente a do subjetivismo idealista, configurada na distinção entre fenômenos e coisas em si mesmas e na afirmação de que nosso conhecimento só diz respeito àqueles. Se, porém, tentamos examinar mais detidamente uma tal distinção, tomando-a como uma idéia a considerar, independentemente da filosofia em que esteja figurando, é de se notar que traz em si uma dificuldade bastante peculiar: se todo o nosso conhecimento é um conhecimento dos objetos tal como nos aparecem, como podemos sequer ter imaginado a possibilidade de serem eles de outro modo? Em princípio, trata-se de algo que não poderia ser-nos indicado pelos próprios objetos, pois neste caso eles mesmos é que já estariam incluindo em sua aparição fenomênica este algo 
mais, e este algo mais deixaria com isto de ser algo mais. Neste sentido, toda a questão, desde seu nascimento, parece não poder ser mais que uma distinção cogitada pelo intelecto humano, sem qualquer contato 'efetivo' com a realidade empírica, na qual 'dualidades' desse tipo não costumam ser encontradas.

Ora, no registro da solução kantiana essa dificuldade se traduz na impossibilidade de aplicar as categorias do entendimento aos objetos cogitados como coisas em si mesmas, pois, mesmo que não se trate de conhecer suas 'propriedades numênicas' (como são em si mesmos), estar-se-ia afirmando sua 'existência numênica' (que são em si mesmos, independentemente do sujeito), algo que só poderia ser feito por meio do emprego da categoria de modalidade 'existência'. ${ }^{3}$ Tal emprego, porém, consistiria em aplicá-la não mais ao domínio fenomênico, em que os objetos só podem ser ditos existentes em sentido relativo (relativamente ao sujeito), mas a um domínio outro em que os objetos pudessem ser ditos existentes em sentido absoluto, isto é, ao domínio de uma realidade considerada existente em sentido absoluto - uma realidade em que o sujeito não mais teria o estatuto de condição necessária, e em que nosso conhecimento perderia novamente sua objetividade, pois perderíamos a capacidade de fazer afirmações dotadas de necessidade e universalidade. Se, com efeito, a solução transcendental se baseia fundamentalmente neste ponto (o sujeito ser condição de possibilidade da realidade), a extensão do uso de uma categoria ao 'em si' dos objetos parece pôr tudo a perder, e deve ser rejeitada. Se, porém, a solução transcendental depende ao mesmo tempo da distinção entre fenômenos e coisa em si, pois que somente assim pode o mundo ser considerado, enquanto fenômeno, como regulado pelo sujeito, recoloca-se o problema da origem da idéia desta distinção ('de onde' a tiramos?), e parecemos cair num círculo vicioso de difícil saída: se só conhecemos os objetos como nos aparecem (condicionados a nós), como podemos saber que existem, ou mesmo que podem existir, independentemente de tal aparição (incondicionados)? Mas se não sabemos que existem ou podem existir independentemente de tal aparição, como podemos afirmar que os conhecemos apenas como aparecem para nós (estando aqui pressuposto que possam existir de outro modo)? Ainda que o tratamento desse 'outro lado' na base de uma possibilidade indique uma terceira 'saída', talvez intermediária, para o tratamento da questão (tratando-se a coisa em si de uma mera possibilidade cogitável), ela não chega a dissipar a dificuldade, pois significaria tão somente trocar a categoria 'existência' pela 
categoria 'possibilidade', e aplicar esta última, também em desacordo com as prescrições da doutrina transcendental, ao 'em si' dos objetos.

De qualquer modo, o que se caracteriza é esse círculo vicioso de difícil saída. Ainda que a aplicação de qualquer categoria ao supra-sensível (isto é, ao que está para além da experiência) - seja ela de existência ou de possibilidade pareça colidir frontalmente com os ensinamentos da Analítica Transcendental, torna-se muito difícil, sem isto, compreender a distinção que está na base de toda a doutrina (entre fenômeno e coisa em si). Neste ponto, podemos juntar-nos a Jacobi e entender bem o significado de sua célebre frase: "se não admitimos a coisa em si, não podemos entrar no sistema kantiano; admiti-la significa ter de sair do sistema" (citada, por exemplo, em Philonenko 8). Como talvez o próprio Kant nos dissesse, porém, esta questão é uma daquelas questões que a razão, ao mesmo tempo em que não pode responder, não pode igualmente deixar de lado (Kant 4, AI), e ainda que a circularidade do problema não pareça afastada, como dissemos, nas passagens em que ele próprio a aborda, tentemos confrontar algumas delas de modo a ver se não há alguma 'saída' que melhor as harmonize. No parágrafo 32 dos Prolegômenos, por exemplo, Kant afirma:

De fato, se enxergamos, com tanto mais razão, os objetos dos sentidos como meros fenômenos (als bloße Erscheinungen), admitimos porém ao mesmo tempo que eles repousam sobre uma coisa em si mesma como seu fundamento, ainda que não saibamos como ela é constituída, e só tomemos conhecimento de seu fenômeno, isto é, do modo pelo qual nossos sentidos são afetados por esse algo desconhecido. $\mathrm{O}$ entendimento, portanto, ao mesmo tempo em que admite fenômenos, aceita também a existência de coisas em si mesmas, e podemos então dizer que a representação desses seres que subjazem aos fenômenos (portanto meros seres inteligíveis) é não apenas permitida, como ainda inevitável. (Prol., Ak. IV, 314/5)

Essa é, como se pode facilmente notar, uma das passagens em que Kant parece autorizar a interpretação realista, visto que, embora fazendo a ressalva de que não sabemos como o objeto, considerado enquanto coisa em si, é constituído (wie es an sich beschaffen sei), ele ao mesmo tempo afirma que é a aparência (fenômeno, Erscheinung) do objeto em si que conhecemos, na medida em que nossos sentidos são afetados por ele, ou por 'esse algo desconhecido' (von diesen unbekannten Etwas). Isto quer dizer que o objeto é um 
só, mas o fato de o conhecermos de um determinado modo (como fenômeno) indica necessariamente sua existência em sentido forte, ou seja, como algo que existe independentemente do sujeito e que é capaz de agir sobre a sensibilidade, afetando-a. Afinal, como nos diz Kant em outra parte, o contrário desta suposição "seria a proposição absurda de que a aparência (Erscheinung) existe sem algo para aparecer (ohne etwas, was da erscheint)" (Kant 4, B XXVII). Nesta medida, simplesmente não haveria falar em fenômeno sem falar em coisa em si, e a afirmação da existência de um objeto como fenômeno contém em si, ao mesmo tempo, a afirmação de sua existência como coisa em si, tratando-se esta última tão somente do 'outro lado da mesma moeda'.

Estando essa distinção, contudo, na base de todo o sistema de nosso conhecimento teórico, já que a objetividade do mesmo repousa no fato de a totalidade da experiência possível poder estar submetida às condições formais subjetivas da sensibilidade e do entendimento, vemo-nos então levados à surpreendente conclusão de que a afirmação da realidade dos objetos e da realidade em sentido absoluto (sua existência autônoma em relação ao sujeito) está também na base do sistema, como elemento constitutivo da objetividade teórica. Afinal, se esta afirmação está contida na distinção fenômeno/coisa em si, que por seu turno é requisito para se efetuar a submissão da experiência ao sujeito, a existência do mundo precede logicamente a ação cognitiva do sujeito, que passa a consistir então num 'recorte' da realidade operado por nossas faculdades de conhecimento, e não na 'construção' da mesma. Ainda que nossas faculdades de fato delimitem a objetividade de nosso conhecimento, na medida em que o 'constróem' sobre o material efetivamente recebido pela sensibilidade, elas jamais poderiam ser determinantes da própria realidade, que, considerada em si mesma, deve preceder sua atuação. Embora esta conclusão pareça, a princípio, ir contra a essência da doutrina transcendental, que define a objetividade em termos das categorias do entendimento e das formas da sensibilidade, e não em termos da realidade considerada em sentido absoluto (pois isto seria retroceder em relação às ressalvas idealistas da filosofia moderna), trata-se, como já dissemos, de uma interpretação possível para a afirmação de que o 'ser dado de fora' dos objetos é também um requisito dessa objetividade - uma interpretação que lê este 'de fora' como sendo 'realmente de fora', isto é, como uma origem estranha ao sujeito.

A leitura de Bernard Rousset, em La doctrine kantienne de l'objectivité 
(Rousset 9), caminha numa tal direção, e, reforçando a corrente dos leitores realistas de Kant, é vista como original justamente por enfatizar a ligação necessária entre a objetividade teórica e a afirmação da realidade da coisa em si, sendo esta elemento constitutivo daquela. ${ }^{4}$ Tendo em vista passagens como a que citamos, bem como a 'Refutação do Idealismo', que, como dissemos, foi introduzida na segunda edição da Crítica da razão pura, e em que Kant procura marcar claramente as diferenças entre o seu idealismo transcendental e os idealismos de Descartes e Berkeley, por ele definidos respectivamente como problemático e dogmático, Rousset procura mostrar em que medida a afirmação da realidade dos objetos (dos quais o fenômeno e a coisa em si são os 'dois lados da moeda') é crucial para todo o sistema da doutrina kantiana com respeito ao conhecimento teórico:

A Refutação do Idealismo tem precisamente por fim estabelecer que uma existência exterior é imediatamente dada na intuição empírica do sentido externo e que ela não se reduz à mera existência de representações em nós, no sentido interno, porque se trata de um sentido que é verdadeiramente externo e que é, ainda, uma passividade. O criticismo não mais se opõe ao idealismo empírico de Berkeley apenas por ser uma teoria da ciência que demonstra a possibilidade de uma necessidade objetiva graças ao a priori, contra a contingência subjetiva defendida pelos empiristas: ele se lhe opõe também como um verdadeiro realismo que mostra que a matéria empírica contém imediatamente uma realidade e uma exterioridade efetivas distintas da interioridade da representação e da idealidade de suas formas. Isto significa que o realismo empírico é também um realismo material porque o idealismo transcendental é apenas um idealismo formal: em outras palavras, quando a consciência está em posse de um conteúdo preenchendo suas faculdades, ela está em relação direta com um termo exterior a ela mesma e independente de sua atividade. A doutrina kantiana da objetividade teórica é um realismo porque afirma que a presença de algo é para o sujeito uma relação ao ser (Rousset 9, p. 337-8).

Rousset estabelece desse modo uma leitura realista que se mostra, no dizer de Philonenko, uma "inovação ousada" (Philonenko 8, p. 162), já que conflitante com visões predominantes em toda a tradição de comentadores e críticos de Kant, e talvez mais radical que a de outros intérpretes realistas. ${ }^{8} \mathrm{Se}$, retomando a dificuldade envolvida na perspectiva de aplicação da categoria de 
existência a algo não dado na experiência, sondamos a obra de Rousset a este respeito, vemos que sua solução para o problema de fato se baseia na idéia de que, se os objetos são unos, constituindo o seu lado fenomênico aquele que nos aparece, e seu lado em si, aquele a que não temos acesso, a mera afirmação de sua existência fenomênica já implica sua existência 'não apenas fenomênica'. Toda a dificuldade em torno da questão estaria na verdade na confusão entre dois sentidos distintos da coisa em si, que aparece ora como fonte real de nossa representação sensível, ou o ser que nos afeta ("em si imanente"), ora como algo que esteja para além de tudo que possa afetar-nos, isto é, realmente para além de toda experiência possível ("em si transcendente"). Segundo Rousset, sempre que Kant se refere à total incognoscibilidade do 'em si', está se referindo a este segundo tipo, de modo a posicionar-se contra a tradição dogmática, enquanto o primeiro tipo, embora também incognoscível quanto às suas propriedades, teria porém sua existência determinada em nossa sensibilidade, sendo a condição material dos objetos de nosso conhecimento (Rousset 9, p. 167).

Philonenko, em seu comentário ao livro de Rousset, ainda que reconhecendo as virtudes da obra, faz, entre outras, duas observações que podem contribuir para a presente discussão: de um lado, contesta a originalidade dessa distinção entre um "em si imanente" e um "em si transcendente", já presente na obra de Adickes (Philonenko 8, p. 174; cf. Adickes 1); de outro, considera insuficiente o rol de citações kantianas 'realistas' usadas por Rousset para sustentar sua tese principal (da coisa em si como elemento constitutivo da objetividade teórica), visto haver toda uma série de passagens 'idealistas' que apontam em outro sentido (Philonenko 8, p. 171). É evidente que, se Rousset pretendia estabelecer uma leitura radicalmente alternativa à tradição, o recurso a uma idéia já testada e explorada, como um argumento central, é em princípio pouco fortalecedor de sua posição. Mas é também evidente que isto não basta para que se desconsidere a hipótese de leitura por ele proposta, sendo antes de maior importância considerar uma dessas outras passagens que, na obra kantiana, sugerem a leitura oposta - como, por exemplo, a seção intitulada 'Idealismo Transcendental como Chave para a Solução da Dialética Cosmológica Transcendental', em que Kant, retomando lições da Estética e da Analítica de modo a precisar o sentido do seu idealismo (transcendental), faz as seguintes afirmações: 
(...) todos os objetos de uma experiência para nós possível não passam de fenômenos, isto é, meras representações - as quais, além de como as representamos, como corpos extensos ou séries de mudanças, não possuem nenhuma existência auto-suficiente (an sich gegründete Existenz) fora do intelecto humano. (...) O espaço e o tempo, e com eles todos os fenômenos, não são em si mesmos coisas, mas apenas representações, e não podem existir fora de nosso intelecto. (...) trata-se aqui apenas de um fenômeno no espaço e no tempo, ambos os quais não são determinações das coisas em si mesmas, mas sim da sensibilidade; portanto tudo o que seja dado no espaço e no tempo (fenômenos) não é em si algo (an sich Etwas), mas meras representações que, se não dadas em nós (na percepção), não podem ser encontradas em parte alguma. (Kant 4, B 518-22).

Como se observa, esse trecho colide frontalmente com aquele extraído do parágrafo 32 dos Prolegômenos, já que aqui Kant afirma em termos claros que os objetos, à parte seu ser fenomênico (sua existência relativamente ao sujeito, determinada nas formas da sensibilidade), não possuem qualquer outro ser. É evidente que a referência ao em si tem aqui em vista nossa capacidade cognoscitiva, no sentido de que este outro ser nos é absolutamente inacessível por meio de conhecimento, e não a existência mesma deste outro ser, no sentido de que Kant a estivesse negando em termos absolutos, pois isto seria ir inapelavelmente contra sua própria doutrina, dando vez ao ‘idealismo dogmático’ de Berkeley. De qualquer modo, mesmo em se tratando, como não poderia deixar de ser, do alcance de nosso conhecimento teórico, a afirmação de que este não pode ser estendido, em nenhuma hipótese, ao em si dos objetos ratifica a inadequação das categorias para a tarefa, afastando-se a possibilidade de uma leitura realista como a de Rousset (inclusive por tratar-se aqui do 'em si imanente' e não do 'em si transcendente'). A partir desse trecho, com efeito, a leitura 'idealista' volta a se afigurar mais adequada, devendo a distinção fenômeno/coisa em si ser vista como introduzida por nosso intelecto, e o conceito de coisa em si, ou númeno, como um conceito sem realidade objetiva, meramente problemático e limitativo.

Para Rousset, essa interpretação da questão invalidaria a 'Refutação do Idealismo', pois, embora sem dúvida marcando a diferença de Kant em relação a Berkeley, não conseguiria dar conta de estabelecer a sua devida distância em relação a Descartes, pois estaria mantendo a exterioridade dos objetos sensíveis no nível da mera representação e, assim, não garantiria a existência dos 
mesmos (Rousset 9, p. 142). A idéia de uma 'exterioridade interna', porém, que Rousset considera insuficiente, embora reconhecendo ser a idéia chave das interpretações 'não realistas' (idem, pp. 43-47), apresenta uma proposta de diferenciação entre as filosofias de Kant e de Descartes que, se não tão radical quanto a de Rousset, ao menos parece compatibilizar-se melhor com as tantas passagens de cunho notadamente idealista (como a acima citada). ${ }^{6}$ De acordo com essa proposta, é preciso supor três níveis de cogitação do ser do objeto: como representações sensíveis; como intuições externas; como algo de incerto (coisas em si) (cf., a esse respeito, Han 3). Se, para Kant, a interioridade (o in uns) pode ser repartida nos dois primeiros níveis, correspondendo o segundo à exterioridade (außer uns) que é por ele insistentemente afirmada, sobretudo na 'Refutação', para Descartes inexistiria tal repartição, referindo-se o seu idealismo apenas ao primeiro, e estendendo-se a dúvida cética a uma exterioridade que compreenderia indistintamente o segundo e o terceiro níveis. O ponto chave da diferença está na subjetividade do espaço e do tempo como formas necessárias de toda e qualquer intuição, de tal modo que a existência dos objetos no espaço (Existenz-in-Raume), fora de nós (mas ainda 'em nós'), não pode, como em Descartes, ser posta em dúvida, mas ao mesmo tempo não pode levar à conclusão afirmativa da existência dos mesmos objetos em sentido absoluto (an sich gegründete Existenz), correspondente ao terceiro nível da cogitação do ser dos objetos. Do contrário, estar-se-ia estabelecendo uma identificação entre este e o segundo nível que, numa leitura realista das tantas afirmações da existência exterior dos objetos, implicaria, como aponta Lachièze-Rey, um inadmissível retorno ao realismo transcendental (Lachièze-Rey 5, p. 212).

Partindo também da impossibilidade de uma tal implicação, Lebrun caminha em sentido inverso ao de Rousset, tentando mostrar, neste ponto em consonância com a tradição exegética, que a possibilidade de extensão das categorias ao em si dos objetos compromete toda a objetividade de nosso conhecimento, não podendo a coisa em si ser afirmada, positivamente, no âmbito do saber teórico, e muito menos ser apontada como elemento constitutivo do mesmo. Afinal, se a realidade considerada em si mesma (independente do sujeito) for tomada como dada, no mesmo nível em que são dados os objetos de nossa experiência (fenômenos), o caráter universal das formas subjetivas resta relativizado, e nosso conhecimento, de necessário, passa a contingente, dependendo, para constituir-se, do "acaso feliz" de nossa sensibilidade ser 'tocada' 
pelas coisas em si mesmas, 'vindas' de um ‘outro lado' cheio de mistérios:

(...) a admissão de sua existência (das coisas em si), como por detrás de uma cortina, introduziria em nosso conhecimento a priori uma insuportável fragilidade. Haveria alhures conteúdos que mereceriam o nome de objetos, embora permanecendo subtraídos à jurisdição estabelecida na Analítica. É verdade que nosso conhecimento a priori permaneceria garantido pela equação 'objeto=fenômeno', mas essa equação, ela mesma, seria apenas o efeito de um acaso feliz. Toda interpretação que represente o objeto-fenômeno como a parcela cognoscível da coisa em si deve desembocar, se for conseqüente, nesta conclusão. (Lebrun 6, p. 67).

Do ponto de vista dessa leitura, portanto, a afirmação da existência da coisa em si revela-se não apenas impossível, em face da inaplicabilidade das categorias de 'existência' ou de 'causalidade' ao 'em si' dos objetos, como ainda prejudicial ao sistema do conhecimento teórico salvaguardado pela doutrina transcendental. O conceito de coisa em si, ou númeno, só pode mesmo, de acordo com o ensinamento do próprio Kant em diversas passagens, ser tomado como problemático e limitativo, ou seja, como uma idéia produzida por nosso intelecto com a finalidade de proibir o entendimento de tentar ir além de seus limites (algo a que a metafísica clássica o instigava). Mas o fato de assim o pensarmos, e de podermos mesmo fazê-lo, nada tem que ver com conhecimento, pois este, como insistentemente enfatizado por Kant, deve resultar da conjunção de um conceito com uma intuição - e não pode haver intuição para além das formas da sensibilidade. "Tal é, nos lembra Lebrun, a lectio purissima, a mais conforme à 'Erkenntnisstheorie' da Crítica” (Lebrun 6, p. 61).

Ainda que a presente análise seja talvez por demais sucinta para embasar conclusões a respeito de uma questão tão polêmica, e que os argumentos não mencionados, em defesa tanto das leituras aqui mencionadas como de muitas outras, constituam um campo vasto a explorar, é de se reconhecer, tendo em vista tão somente os delineamentos gerais das interpretações sugeridas, que a última leitura apresentada, presente em Lebrun e em boa parte da tradição, apresenta algumas vantagens em relação à leitura proposta por Rousset. Se, como nos mostrava Philonenko, este último não apresenta em defesa de sua tese uma quantidade suficiente de citações 'realistas', isto se torna mais grave na medida em que a enorme quantidade de citações 'idealistas', em claro con- 
flito com sua posição, não pode por ela ser abarcada consistentemente, já que afirmações como as que apresentamos acima não podem ser compatibilizadas com a afirmação de que a coisa em si é elemento constitutivo da objetividade teórica. ${ }^{7}$ Já a outra leitura teria um potencial notadamente maior de harmonização das diferentes passagens, sob a idéia de que qualquer referência ao em si ('imanente' ou 'transcendente') é necessariamente problemática: as passagens que parecem sugerir um posicionamento realista na verdade são passagens em que Kant está adotando o 'ponto de vista' problemático para poder, a partir de idéias que, estas sim, estão unicamente em nós (no sentido mais forte deste 'in uns'), considerar o âmbito teórico em sua necessária limitação que é ao mesmo tempo toda a sua universalidade (a conformação necessária dos objetos de experiência às formas subjetivas a priori).

Embora seja certo que, se nos deparássemos com a afirmação pura e simples de que a realidade está submetida às condições subjetivas de nossas faculdades de conhecimento, concluiríamos a princípio pelo absurdo da mesma, Kant tenta justamente mostrar que nosso conhecimento só pode ser dito objetivo, em sentido forte (isto é, necessário e universal), se ela for válida. Assim, se é para falar num conhecimento dotado de validade objetiva, precisamos, no mínimo, supô-la válida, e, para que isto se torne logicamente razoável, é necessário delimitar a realidade que está submetida às nossas condições subjetivas como a realidade que conhecemos, acompanhando-se-lhe imediatamente a idéia de que é perfeitamente possível (e até provável, diríamos) não ser esta realidade a única (ou a realidade em sentido absoluto). Isto nunca quis dizer, contudo, que esta realidade não seja nosso único ponto de partida (pois "todo nosso conhecimento começa na experiência" [Kant 4, B 1]) e nosso único ponto de chegada (pois o único uso legítimo das categorias é sua aplicação à experiência) - em outras palavras, nossa única realidade. Isto quis dizer apenas que, na medida em que precisávamos compreender de que maneira toda a realidade podia estar submetida a nossas faculdades, precisamos considerar a idéia de uma realidade não submetida a nossas faculdades, isto é, de uma realidade em si, por oposição àquela outra realidade, dita então fenomênica. A idéia de coisa em si, portanto, embora sem dúvida elemento essencial de toda a filosofia crítica (já que possibilitadora da 'Revolução Copernicana'), não poderia jamais ser 'transferida' para o interior do sistema de nosso conhecimento teórico, visto resultar de uma reflexão a ele exterior: como idéia, ou 
conceito problemático, ela permite tanto compreender a objetividade de nosso conhecimento, como estabelecer sua circunscrição ao domínio da experiência (que é a única realidade para nós). Do ponto de vista de uma tal reflexão (de nosso pensar), seria evidentemente absurdo imaginar que esta 'realidade para nós' não é 'real', mas do ponto de vista de nosso conhecimento empírico, que nunca 'saiu' ele próprio da experiência, a mera pergunta 'Esta realidade é real?' seria já um disparate, e com ela a distinção fenômeno/coisa em si.

Em geral, na filosofia kantiana, a única saída para um círculo vicioso consiste em adotar diferentes pontos de vista (talvez a estratégia chave do criticismo). E a presente problemática, se adotamos a interpretação que recusa a afirmação da realidade da coisa em si, aceitando-a apenas como conceito problemático, não parece fugir à regra: do ponto de vista do conhecer, não existe outro ser além de nossa representação sensível; do ponto de vista do pensar, a suposição de que ao fenômeno corresponde um ser em si é mais razoável que supô-lo destituído de ser (uma 'mera representação'). Este é, parece-nos, o sentido em que deve ser interpretado o célebre trecho, já mencionado, em que Kant considera absurda a idéia de uma aparência sem um algo para aparecer:

É provado na parte analítica da Crítica: que o espaço e o tempo são meras formas da intuição sensível, e portanto meras condições da existência das coisas como fenômenos; que ainda nós só possuímos conceitos do entendimento, e portanto elementos para o conhecimento das coisas, na medida em que a esses conceitos possa ser dada uma intuição correspondente; e que, portanto, nós não podemos ter qualquer conhecimento de um objeto como uma coisa em si mesma, mas apenas como objeto de uma intuição sensível, isto é, fenômeno. E de tudo isso se segue necessariamente a limitação de todo conhecimento especulativo possível da razão aos meros objetos da experiência. Ao mesmo tempo, porém e isto não deve ser esquecido -, tem de ficar garantida a possibilidade de nós pensarmos esses mesmos objetos como coisas em si, ainda que não possamos conhecê-los. Do contrário se seguiria a proposição absurda de que a aparência existe sem algo para aparecer. (Kant 4, B XXVI; grifo nosso).

Ora, se a filosofia crítica pretendesse restringir toda a nossa atividade intelectual ao intuir e sintetizar objetos, ou seja, à atividade combinada da sensibilidade e do entendimento que constrói os objetos, ela estaria, ao mesmo tempo, impedindo-se a si própria de existir, posto não ser ela resultante de uma 
tal atividade, e sim de uma reflexão a partir da mesma. A restrição que se faz ao emprego das categorias, no sentido de que a elas deve sempre poder corresponder uma intuição sensível, diz respeito tão somente ao estabelecimento de um critério preciso de verificação da realidade dos objetos que construímos por meio de nossos conceitos: só podem ser ditos conhecidos objetos (e portanto conceitos) que sejam garantidamente reais. Mas isto não significa, nem nunca pretendeu significar, que nossa atividade especulativa se esgote aí, posto que o pensar autônomo (independente da experiência) é uma nossa atividade tão natural quanto o conhecer empírico; apenas não se lhe poderá atribuir o estatuto de conhecimento, na medida em que seus conceitos não sejam reais (isto é, que a eles não possa corresponder uma intuição sensível). E é este, precisamente, o caso do conceito de 'em si': fruto natural de nossa reflexão sobre o conhecimento empírico e o todo da experiência, não pode, contudo, jamais ser dito real, visto não poder ser dado nesta mesma experiência.

A ausência de uma tal reflexão, e de um tal conceito, implicaria o risco de uma hipostatização da realidade a que nossos sentidos nos dão acesso, no sentido de que tenderíamos a tomá-la como absoluta. Evitar esta hipostatização é talvez, para Kant, uma preocupação ainda maior do que a de evitar a pretensão de acessar cognitivamente o supra-sensível, pois, ao contrário desta última, já bastante enfraquecida pelo argumento cético, aquela é bem menos perceptível, e suas conseqüências podem ser ainda mais nefastas (já que o homem teria de se enxergar, em todos os sentidos, como inteiramente submetido à necessidade natural). ${ }^{8}$ Ao incrível fortalecimento do conhecimento teórico, garantido como necessário e universal pela Analítica (ele vale necessariamente para toda experiência possível), deve então suceder-se o seu 'enfraquecimento' por meio do mesmo movimento reflexivo e do mesmo conceito que o haviam fortalecido: a noção de em si, que havia garantido seu reinado sobre a totalidade do domínio da experiência, deve agora impedir a extensão desse reinado ao domínio de uma totalidade absoluta da realidade. A imagem ideal, para ilustrar o domínio do conhecimento teórico (compreendendo tanto os dados sensíveis como nossas formas a priori da sensibilidade e do entendimento), a partir dos resultados da primeira parte da Crítica, é a imagem de uma ilha - uma ilha, é verdade, em que tudo está organizado, mas uma ilha que é ao mesmo tempo incomodamente circundada por um oceano de interrogações, de inevitáveis e perigosas interrogações: 
Nós não apenas atravessamos a região do entendimento puro, investigando cuidadosamente cada parte dela, como também aferimos sua extensão e atribuímos a cada coisa seu devido lugar. Esta região é no entanto uma ilha, cercada por fronteiras invariáveis demarcadas pela própria natureza. É a terra da verdade (uma palavra instigante), circundada por um vasto e tormentoso oceano que é o verdadeiro lugar da ilusão (Sitze des Scheins), onde névoas e blocos de gelo que se derretem facilmente forjam a aparência de novas terras, e, iludindo com esperanças vãs o navegador, ansioso por descobertas, conduzem-no a aventuras perigosas que ele nunca abandona, mas que ao mesmo tempo não é capaz de concluir. (Kant 4, B 294).

É evidente que, a partir apenas dos dados de nossos sentidos (sensibilidade), e da faculdade que nos permite organizá-los sob a forma de objetos (o entendimento), a ilha é tudo, e não há oceano. Tais faculdades, porém, não são as únicas que possuímos. Nós possuímos ainda uma faculdade que nos permite operar inferências mediatas, e não apenas imediatas; uma faculdade que nos permite pensar 'por conta própria', enquanto que o pensar do entendimento resume-se a sintetizar informações dos sentidos (se vemos um cachorro, pensamos 'isto é um cachorro')'; uma faculdade que estabelece um ponto de vista reflexivo que não está adstrito ao domínio da experiência e que, ainda que por outro lado adstrito à nossa mais completa subjetividade (o sentido mais forte do 'in uns'), permite-nos 'enxergar', em torno do círculo limitado da experiência, todo um oceano aberto à nossa exploração. Tal faculdade é a razão, e é apenas o seu ponto de vista que permite enxergar a realidade que conhecemos (a ilha) ao lado da realidade em si (o oceano, ou, melhor dizendo, o conjunto da totalidade a englobar ilha e oceano). E, embora feita a ressalva da subjetividade deste outro ponto de vista (por oposição à objetividade do ponto de vista do entendimento, que só enxerga a ilha), e portanto da impossibilidade de vir ele a constituir conhecimento (em sentido forte), a navegação, oceano afora, pode (e deve) ser empreendida. Para tal, porém, a razão (o navegador), na impossibilidade de sondar algo 'fora' de si, deve sondar-se a si própria, e encontrar em si a bússola que deverá guiá-la por essas águas tormentosas, de modo a não incorrer nos mesmos erros que levaram ao naufrágio antigos e experientes navegadores. 
Abstract: The text discusses the problem of Kant's thing-in-itself, presenting two possible views about it: the polemical position of Bernard Rousset (in La doctrine kantienne de l'objectivité), and that of Gérard Lebrun (in Kant et la fin de la métaphysique). The latter is considered to be more plausible regarding Kant's general project.

Key-words: thing-in-itself - idealism - realism - rational

\section{Notas}

1. Schopenhauer foi talvez o primeiro a dar atenção a essa questão. Tendo interesse em fazer uma leitura idealista da filosofia kantiana, pretendeu mostrar a diferença entre as duas edições preferindo a primeira à segunda, e alegando uma 'volta atrás' de Kant. “Que ninguém pretenda conhecer a Crítica da razão pura, nem ter uma idéia clara da doutrina de Kant, se só leu a Crítica na segunda edição ou em uma das seguintes; isto é absolutamente impossível, pois se terá lido um texto truncado, corrompido e, numa certa medida, apócrifo" (Schopenhauer 10, p. 26). 
2. John P. Mahaffy, na Introdução à tradução inglesa do livro clássico de Kuno Fischer (Comentário à 'Crítica da razão pura' de Kant), cita esta passagem do prefácio à segunda edição e, ironizando a leitura de Schopenhauer, endossada por Fischer, afirma: "Contra essa declaração, que expressamente afirma que absolutamente nada mudou no sistema, e que convida o leitor a comparar as duas edições, dizem-nos que a segunda edição é uma obra mutilada, distorcida e depravada, fruto da fraqueza da idade avançada e do medo da opinião pública em Kant!! A fraqueza da idade é mesmo uma boa desculpa para o homem que, depois disso, escreveu e publicou as Críticas do Juízo e da Razão Prática, e o tratado sobre a Religião nos Limites da Razão Pura! O medo dos homens era de fato muito forte no homem que estava à época preparando este último tratado, e que não alterou uma só palavra na sua refutação de toda a teologia especulativa!" (Mahaffy 7, p. XLI).

3. O mesmo problema se verifica nas vezes em que Kant afirma que o 'lado em si' dos fenômenos 'causa' sua aparição para nós. Neste caso, a categoria inadequadamente aplicada seria a de 'causa'. Todavia, sendo o problema o mesmo, e sendo a questão da existência mais importante (já que para 'causar', o 'em si' teria antes que 'existir'), preferimos enfocar a questão precipuamente por este ângulo.

4. A. Philonenko, comentando o livro de Rousset, reconhece a originalidade deste autor justamente no que diz respeito à afirmação do em si como elemento constitutivo da objetividade teórica (Philonenko 8, pp. 160-176).

5. Muitos defenderam a tese de que Kant afirmava a existência da coisa em si, mas nenhum chegou a fazer desta afirmação um elemento constitutivo da objetividade teórica, colocando-a assim, do ponto de vista do conhecimento teórico, ao nível de importância das categorias e das formas da sensibilidade.

6. Lachièze-Rey é assumido por Rousset como principal 'interlocutor idealista'. De acordo com ele, embora o mundo exterior não possa ser "uma simples representação nascendo na espontaneidade do espírito", também não pode ser uma coisa em si (Lachièze-Rey 5, p. 208), de tal modo que a questão tenha de ser resolvida nos quadros mesmos da linguagem idealista (p. 222): tem de haver um nível da subjetividade em que o sujeito é ao mesmo tempo ativo e passivo, se auto-afetando e dando a si próprio o material a que irá aplicar as formas a priori: "a crítica do idealismo conduz assim necessariamente à admissão de uma idealidade material, e não apenas a uma idealidade formal" (p. 241).

7. A saída de Rousset não pode ser outra que a de atribuir a contradição das passagens a uma hesitação de Kant, e tentar mostrar que, ao longo da obra, Kant tendeu a superar esta hesitação na direção do realismo (Rousset 9, pp. 147-153). Não à toa, Rousset aceita de bom grado a tese da mudança de postura entre a primeira e a segunda edições da Crítica da razão pura (idem). Explica-se também por meio disso a importância dada ao Opus Postumum, que Rousset interpreta a seu favor, desde o início do livro (p. 12).

8. A noção kantiana de liberdade se constitui justamente por oposição à 'determinação cega' pelas leis da natureza, e é disto que decorre a imensa importância de se limitar o conheci- 
mento teórico (de experiência) ao meramente fenomênico, evitando-se a sua hipostatização. 9. É evidente que a questão é muito mais complexa. As conclusões mediatas não implicam por si sós o abandono do terreno da experiência. Muito pelo contrário, a grande maioria delas, fruto do uso lógico da razão que complementa o uso do entendimento na construção do conhecimento científico, tem ainda referência exclusiva ao empírico. No entanto, o fato de possuirmos uma tal faculdade é indicativo de que podemos distanciar-nos reflexivamente da experiência (uso puro da razão) e, ainda que operando com conceitos desprovidos de realidade objetiva, construir uma filosofia que permite pensar por um outro ângulo a própria experiência (v. Kant 4, B 355-366). A simplificação da questão se justifica, na presente passagem, pelo interesse em se considerar tão somente a possibilidade deste 'sair reflexivo' dos limites da experiência.

\section{Referências Bibliográficas}

1. ADICKES, E. Kants Lehre von der doppelten Affektion unseres Ich. Tübingen, 1929.

2. DELBOS, V. De Kant aux Post-Kantiens. Paris, Aubier, 1992.

3. HAN, J. Transzendentalphilosophie als Ontologie. Würzburg, Königshausen u. Neumann, 1988.

4. KANT, I. Kritik der reinen Vernunft. Berlim, Georg Reimer, 1911, Vol. III 
(Akademie-Ausgabe).

5. LACHIÈZE-REY, P. L'idéalisme kantien. Paris, Vrin, 1950.

6. LEBRUN, G. “A aporética da coisa em si”. In: Sobre Kant. São Paulo, Iluminuras, 1993.

7. MAHAFFY, J.P. “Introdução". In: FISCHER, K. A commentary on Kant's Critick of pure reason. New York, Garland, 1976.

8. PHILONENKO, A. Études kantiennes. Paris, Vrin, 1982.

9. ROUSSET, B. La doctrine kantienne de l'objectivité. Paris, Vrin, 1967.

10. SCHOPENHAUER, A. Critique de la philosophie kantienne. Paris, Felix Alcan, 1912. 